\title{
Monitoring of the Interaction of Chromium (VI) on the Growth Profile of Chlorophyceae Marine Microalga Chlorella vulgaris in Controlled Laboratory Condition
}

\author{
Sucheta Sadhu ${ }^{1 *}$ and Kirubagaran R. ${ }^{2}$
}

\begin{abstract}
Chromium (Cr) is ubiquitously present in the aquatic environment. From various natural and anthropogenic sources $\mathrm{Cr}$ (VI) reaches to the aquatic ecosystem through weathering and surface runoff. The nature of metals is conservative which leads to the buildup of metal concentration in aquatic system. Microscopic phytoplankton imbibes these metal ions as nutrient irrespective of their essentiality and eventually incorporates to various in situ assimilatory processes. In this study, we report the interactive effect of $\mathrm{Cr}$ (VI) on the Chlorophyceae marine microalga Chlorella vulgaris (NIOT-74, NCBI Accession No: JF894250.1) during the exponential growth phase of the cells on its growth profile and bioconcentration factor in laboratory condition.
\end{abstract}

Keywords - BCF, Chlorella vulgaris, growth profile, Cr (VI).

\section{INTRODUCTION}

$\bigcup_{e}$ HROMIUM (VI) is ubiquitously present in the aquatic environment. Due to the non degradable nature of metal, it keeps accumulating in the environment after mobilizing through run-offs metallurgical wastewater (June et al., 2010) from source to the sink. As a result of this, the plethora of metal xenobiotics builds-up in the aquatic ecosystem. To maintain the homeostasis of the aquatic ecosystem and its surroundings, the total ion pool is regulated in terms of its mass balance. Monitoring of the environmental and physiochemical parameters of the aquatic system reflects some insight about the aquatic environment but it fails to forecast about the growth profile of the microalgae. Microalgae form the base component of the food chain of the natural environment and are invariably affected by insidious metal ions. Microscopic phytoplankton imbibes these metal ions as nutrient irrespective of their essentiality and eventually participates to various in situ assimilatory processes. There are numerous studies available on the interaction of metal and microalgae. The quantitative studies on metal ions are scanty. Recently, many technologies have been opted to mitigate the metal pollutions in the aquatic environment. Literature reveals chemical treatment, use of adsorbent, incineration; land fill,

Sucheta Sadhu ${ }^{1 *}$ is with the National Institute of Ocean Technology, Chennai-600100 and Sathyabama University, Chennai-600119, Tamil Nadu, India..

Kirubagaran R. ${ }^{2}$, is with the National Institute of Ocean Technology, Chennai-600100, Tamil Nadu, India. biological treatment etc. depending on the pollutant criteria these methods are suitable but the concern on secondary pollutant generation still remains in debatable condition. Biological mitigation processes have been proven as green technology to detoxify metal xenobiotics or toxicants as the toxicants gets converted into the nontoxic entity of the corresponding metal through in situ cellular mechanism. The challenges pops-up over here is how best this cellular efficiency can be utilized in terms of metal specificity, in terms of metal concentration and furthermore the biotic and abiotic factors involved during the process. Though biological mitigation goes hand in hand with green technology, yet it is not devoid of challenges in this in view of secondary pollutant generation. Recent studies indicate the detoxification property of microalgae (Jeewan et al., 2014), however, yet there is a need to bridge the lacuna in terms pollutant specificity, suitable species selection, duration of exposure and aftermath fate of the species upon exposure into the particular metal xenobiotics. Use of biological arm to gun down the toxic xenobiotics seems towards a win-win situation.

In this study, we report the interactive effect of Cr (VI) on the Chlorophyceae marine microalga Chlorella vulgaris (NIOT-74, NCBI Accession No: JF894250.1) in triplicate against control over the exponential growth phase of the cells on its growth profile and bioconcentration factor in laboratory condition.

\section{MATERIALS AND MethodOlOGY}

\section{A. The experimental method}

The experiment was framed based on the Organization for the Economic Cooperation and Development (OECD 201) protocol.

\section{B. Cultivation of Microalgae and Growth Media}

The axenic monoculture of the marine microalga Chlorella vulgaris (NIOT-74, NCBI Accession No: JF894250.1) was received from NIOT's marine microalgal collection bank. The culture was grown in filtered seawater enriched with $f / 2$ media. The cultures were acclimatized in experimental condition upto $5^{\text {th }}$ generation. The experiments were carried out exposing the cells in five dissimilar concentrations of $\mathrm{Cr}$ (VI) against control amid $54 \mu \mathrm{mol} \mathrm{m} \mathrm{s}^{-2}$ photosynthetically active radiation (PAR) intended for 12:12 h (dark: light) photoperiod. The 
cultures were swirled gently thrice daily to prevent cell clumping.

\section{Toxicant}

Potassium dichromate $\left(\mathrm{K}_{2} \mathrm{Cr}_{2} \mathrm{O}_{7}\right)$, MERCK, was used to prepare $\mathrm{Cr}(\mathrm{VI})$ stock solution.

\section{D.Treatment}

An initial inoculam of the axenic monoculture of Chlorella vulgaris was inoculated in the Erlenmeyer flask $(500 \mathrm{~mL})$ which contained $200 \mathrm{~mL}$ of seawater enriched with $\mathrm{f} / 2$ media. The culture flasks consisting of five dissimilar concentrations of $\mathrm{Cr}(\mathrm{VI})$ ranging from 50 to $652 \mu \mathrm{g} / \mathrm{mL}$ were supplied in triplicate against control. The five concentrations of $\mathrm{Cr}$ (VI) were selected for the above experiment was on the basis of results of a range finding test conducted earlier.

\section{E. Measurement of Growth Parameters}

Algal cells, cultured for different durations at various range of concentrations were counted using haemocytometer by visualizing under a microscope (Karl Zeiss Axioscope2).

\section{F. Determination of Dry Weight}

Dry weight was measured following the protocol given by Zhu and Lee, 1997. Data were expressed as $\mu \mathrm{g} \mathrm{mL}^{-1}$ algal suspension.

\section{G. Metal Analysis}

The uptake of $\mathrm{Cr}$ (VI) in cells was determined by ICP-OES (VARIAN 725-ES) after harvesting. Also the corresponding media and matrix were analyzed as prescribed by Grass hoff et al. with little modification. Alga was harvested at $96 \mathrm{~h}$ by centrifugation (4000g; ca.10000 rpm) for 15 min. All lyophilized algal biomass was weighed and then digested with concentrated ultra-pure $\mathrm{HNO}_{3}$ and $\mathrm{H}_{2} \mathrm{O}_{2}$ (30\%) (1:4) in pre cleaned, leaded, $100 \mathrm{~mL}$ Teflon vessels. After digestion, the samples were analyzed for metal content by ICP-OES. Blanks and spikes were analyzed to validate the digestion process of spectroscopic analysis, obtaining 95\% recovery. In addition, $0.5 \mu \mathrm{g} / \mathrm{mL}$ of multi-elemental standard was analyzed upon every 10 samples to monitor the matrix effects on the analytes and for quality assurance and quality control.

\section{H. Calculation of BCF}

The BCF was calculated as defined by Brooks and Rumbsy (1965).

\section{G. Statistics}

Results were tested by one-way Analysis of Variance (ANOVA). ANOVA effects and treatments were considered significant when $p<0.05$.

\section{RESUlTS AND DISCUSSION}

Microalgal phenotypic characteristics get impaired due to heavy metal exposure. The results during our investigation reveal that the duration and exposure concentration of heavy metals leads to retardation in growth profile of the exposed microalga. The alga was found to tolerate high concentration $\left(652 \mu \mathrm{g} \mathrm{mL}^{-1}\right)$ of $\mathrm{Cr}(\mathrm{VI})$. The changes observed were found to be significant $(p<0.05)$ at all concentrations and durations as compared to control. All experimental values reported in triplicate and based on Mean \pm S.D.

Our results show congruency with the results of Horcsik et al. (2006), June et al., (2010) and Sucheta et al. (2016) too. Metals at lower concentrations is desired for the nutrition of microalgae, however, it is reported that chromium is not an essential (Sharma et al., 2015) metal for microalgal nutrition or to perform cellular functions.

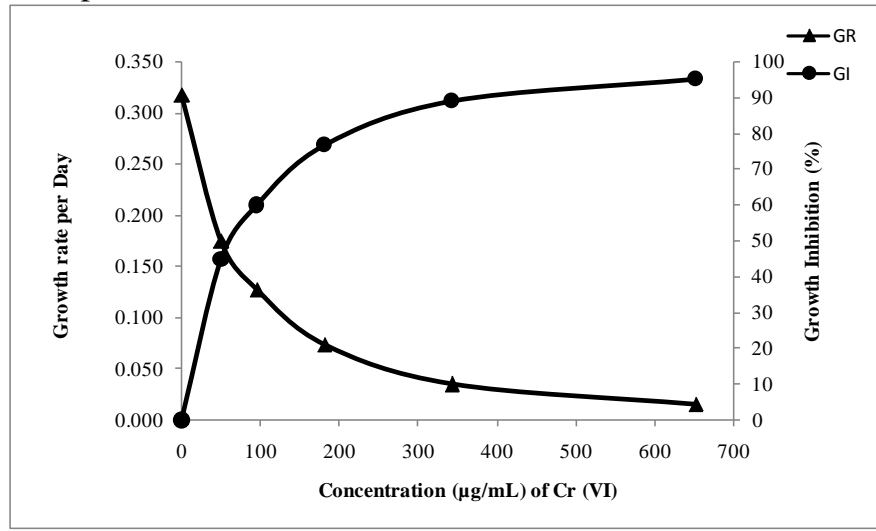

Fig1. Growth rate and growth inhibition profile of $C$. vulgaris during $\mathrm{Cr}$ (VI) exposure at $96 \mathrm{~h}$.

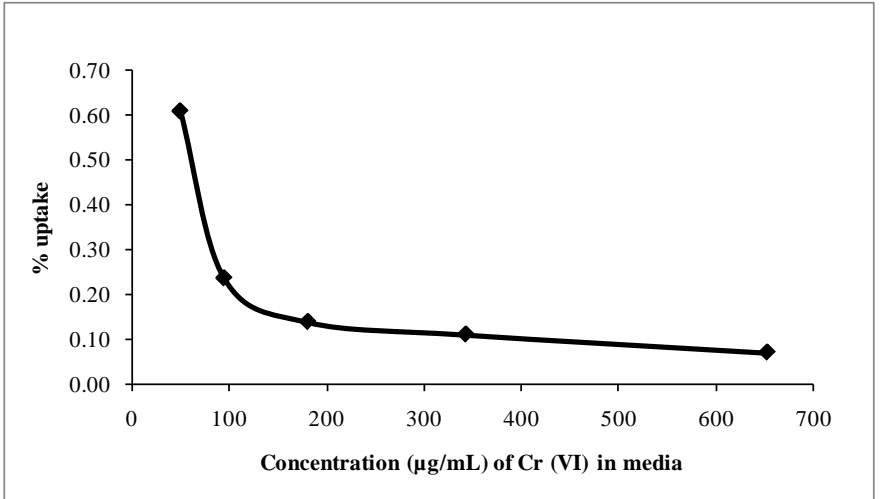

Fig2. Correlation of Cr (VI) uptake at different $\mathrm{Cr}$ (VI) exposure concentrations.

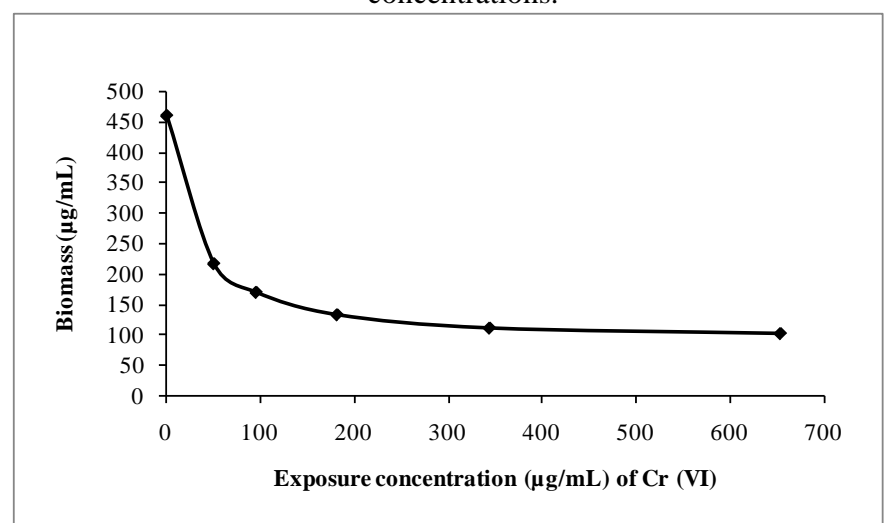

Fig3. Biomass profile at different $\mathrm{Cr}$ (VI) exposure

The growth retardation (Fig1.) of $C$. vulgaris can be attributed to the existence of the $\mathrm{Cr}$ (VI) itself. Cr (VI) accelerates to generate the free radical during in situ cellular assimilation process. Data analysis reveals that the \% uptake of metal (Fig2.) is showing a declining trend with increasing exposure concentration.

Biomass is following a decline (Fig3.) trend as the exposure 
concentration of Cr (VI) is in increasing order. At harvest, a prominent reduction (Fig4.) of $\mathrm{Cr}$ (VI) was observed indicating the bioremoval efficiency of $C$. vulgaris.

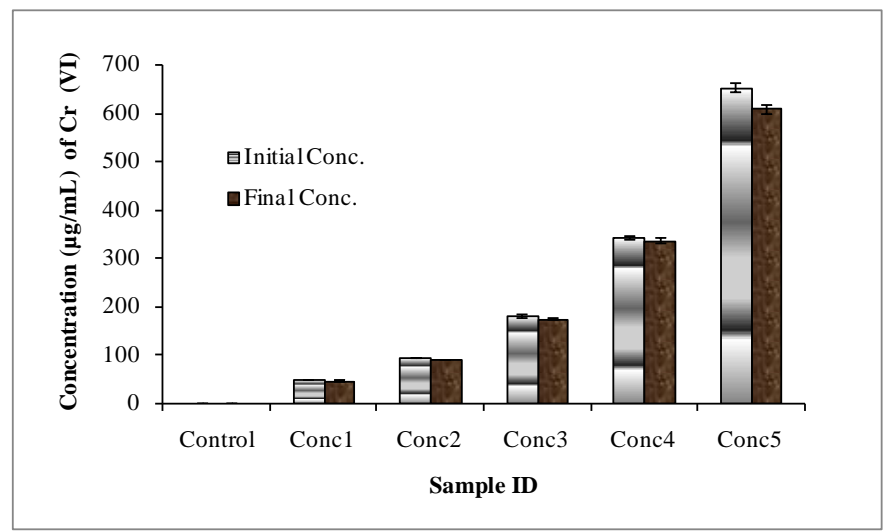

Fig4. Cr (VI) removal profile at $96 \mathrm{~h}$ during harvest.

\section{CONCLUSION}

In conclusion, in this experiment it is found that the $C$. vulgaris can tolerate up to $652 \mu \mathrm{g} / \mathrm{mL}$ of $\mathrm{Cr}$ (VI), however \% accumulation is very less as the alga is exposed to higher concentration, though the removal efficiency increases with increasing exposure concentration of $\mathrm{Cr}(\mathrm{VI})$.

\section{ACKNOWLEDGMENT}

The acknowledgment goes to Dr. R. B. N. Prasad, Formerly Director, for extending the ICP-OES facility at IICT, Hyderabad. SS is thankful to the Director, ESSO-National Institute of Ocean Technology, Chennai, to carry out this work as a part of Doctoral studies. The authors thank the Ministry of Earth Sciences, Govt. of India, New Delhi, for financial assistance.

\section{REFERENCES}

[1] S. Sucheta and R. Kirubagaran, "Monitoring of the growth profile and bioconcentration factor of haptophyceae marine microalga Pavlova lutheri during $\mathrm{Cr}$ (VI) exposure", Renaissance in aquatic science, submitted for publication.

[2] C. J. Zhu and Y. K. Lee, "Determination of biomass dry weight of marine microalgae”,Journal of applied phycology, 1997; 9:189-194 . http://dx.doi.org/10.1023/A:1007914806640

[3] Organization for the Economic Cooperation and Development (OECD) 201: OECD guidelines for the testing of chemicals: Freshwater alga and cyanobacteria, growth inhibition tests.

[4] Chromium in drinking water: Guidelines for drinking-water quality, $2^{\text {nd }}$ ed. Vol.2. Health criteria and other supporting information. World Health Organization, Geneva, 1996.

[5] Jeewan Jyoti and Mamta Awasthi, "Bioremediation of wastewater chromium through microalgae: A review”, International journal of engineering research \& technology, ISSN: 2278-0181, vol. 3(6), pp. 1210-1215, June 2014.

[6] Zsolt Horcsik, Viktor Olah, Arpad Balogh, Ilona Meszaros, Laszlo Simon and Gyula Lakatos, "Effect of chromium(VI) on growth, element and photosynthetic pigment composition of Chlorella pyrenoidosa" Acta Biologica Szegediensis, vol. 50(1-2), pp. 19-23, 2006.

[7] A. A. Fathi, A. M. El-Shahed, M. A. Shoulkamy, H. A. Ibraheim and O. M. Abdel Rahman, " Response of Nile water phytoplankton to the toxicity of cobalt, copper and zinc”, Journal of Environmental toxicology, vol. 2(2), pp. 67-76, 2008.
[8] Oghenemise Abirhire, "Long-term uptake of heavy metals by microalgae”, Journal of academia and industrial research, vol. 1(6), pp. 290-192. ISSN: 2278-5213, 2012.

[9] June Owen O. Nacorda, Milagrosa R. Martinez-Goss and Nerissa K.Torreta, "Bioremoval and bioreduction of chromium (VI) by the green microalga, Chlorella vulgaris Beij., isolated from Laguna de Bay, Philippines”, vol. 139(2), pp. 181-188, December 2010.

[10] Gupta Shilpi, Singh Shilpi, Sharma Sunita, "Tolerance against heavy metal toxicity in cyanobacteria: role of antioxidant defense system”, International journal of pharmacy and pharmaceutical sciences, vol. 7(2), 2015.

[11] Brooks R. R. and Rumsby M. G., "The biogeochemistry of trace element uptake by some New Zealand bivalves”, Limnology and Oceanography, vol. 10, pp. 521-527, 1965. http://dx.doi.org/10.4319/lo.1965.10.4.0521

Sucheta Sadhu ${ }^{1 *}$ has earned her bachelor's degree from Asansol Girls' College under Burdwan University in 2001. She has bagged her Master's degree from Indian Institute of Ecology and Environment, New Delhi under Sikkim Manipal University of Health Medical and Technological Sciences in 2004 in Ecology and Environmental Science and followed by in 2007 she has earned her M.Phill degree in Environmental Science from the University of Jadavpur, Kolkata. At present she is perusing her Ph. D degree from Sathyabama University, Chennai, India and simultaneously she is working as Project Scientific Assistant in Marine Biotechnology division of ESSO-NIOT, Chennai since 2010 till date.

R. Kirubagaran ${ }^{2}$, Scientist-G, is heading the Marine Biotechnology division of ESSO-NIOT, Chennai. He is a life member in the Indian Science Congress Association. Also, Dr. Kirubagaran is a member of National Biodiversity Authority of Coastal Aquaculture Authority of India. Dr. Kirubagaran is also serving as Member Secretary of the National Task Force on Ballast Water Management. 